\title{
IDENTIFICATION OF SIGNIFICANT FACTORS AFFECTING POTATO TUBER YIELD FOR PRECISION MANAGEMENT OF SOIL NUTRIENTS
}

\author{
Humna Khan ${ }^{1}$, Bishnu Acharya ${ }^{1}$, Travis Esau ${ }^{2}$, Aitazaz Farooque ${ }^{1}$, Farhat Abbas ${ }^{1}$, Qamar \\ Zaman $^{2}$ \\ ${ }^{1}$ Faculty of Sustainable Design Engineering, University of Prince Edward Island, Charlottetown, \\ Prince Edward Island, Canada \\ ${ }^{2}$ Department of Engineering, Dalhousie University, Truro, Nova Scotia, Canada
}

\begin{abstract}
Understanding the relationships between soil properties and their effect on tuber yield is an important component of precision management of soil nutrients. This study investigates the relationships between soil properties and tuber yield to provide a better understanding of their variation within the field. Two potato fields were selected in Prince Edward Island, Canada and grid sampling strategy was established at each site for sampling. Soil samples were collected from each grid and analyzed for $\mathrm{pH}$ and soil organic matter (SOM). The slope, volumetric moisture content $(\theta \mathrm{v})$, soil electrical conductivity components including horizontal coplanar geometry (HCP) and perpendicular coplanar geometry (PRP), Normalized difference vegetation index (NDVI), and tuber yield data were also collected from each grid. The significant correlation between the HCP, PRP, $\theta \mathrm{v}$, Slope, NDVI and tuber yield suggested that tuber yield is greatly influenced by variations in all these soil and crop parameters. Multiple regression models explained up to $77 \%$ of the variability in tuber yield as a result of all soil parameters. Stepwise regression analysis reported that HCP, PRP and NDVI explained up to $76 \%$ of the variability in tuber yield within the selected fields. There existed a positive correlation between HCP, PRP, NDVI and yield, which emphasizes the need to develop management zones on the basis of soil electrical conductivity and NDVI. Site-specific fertilization based on soil management zones can mitigate soil variability, enhance input use efficiency, increase profit margins and reduce environmental risks.
\end{abstract}

Keywords: Correlation analysis, regression analysis, soil parameters, potato tuber yield 